\title{
Post-closure funding initiatives to facilitate custodial transfer and relinquishment of mining tenure
}

S Mackenzie Mine Earth Pty Ltd, Australia

\begin{abstract}
The aim of mine closure works is usually to minimise residual liability to enable the responsibility for land management to be transferred to a custodial authority. The accepted approach to relinquish mining tenure after closure works is to measure performance against agreed objectives and criteria over a period of time, to demonstrate success to key stakeholders. The relevant custodial authority may, however, be unwilling to inherit the responsibility for managing closed mines and ongoing closure liabilities in perpetuity.

There are very few examples in Western Australia where a closed mine has been relinquished to the State Government in a coordinated manner. There are examples, however, where Governments have inherited legacy mines and associated closure liabilities, where the mine operator has been unable to meet their closure obligations.

There are examples from around the world where mine operators have established long-term, self-perpetuating funding initiatives as a mechanism to facilitate custodial transfer of mining areas and coordinated relinquishment of mining tenure. Such initiatives can provide financial surety in the event of foreseen or unforeseen closure risks, provide for organisation and management of a custodial body, provide an ongoing benefit to the community or the environment, and can fund ongoing activities for a closed mine.

Self-perpetuating funds and other mechanisms that buffer the exposure that a custodial authority has to residual liabilities and risks, in concert with demonstrated closure success, may encourage Western Australian regulators to more readily consider relinquishment applications for mining tenure. This paper reports on some of the long term funding initiatives that have been applied globally.
\end{abstract}

\section{Introduction}

Mineral development in Western Australia is regulated and administered under the Western Australian Mining Act 1978 and mining tenure is issued pursuant to the Mining Act. Once mineral development is complete closure works are typically implemented, whereby mining infrastructure is removed and disturbed areas are rehabilitated. Typically the aim of closure works is to minimise residual liability to enable the responsibility for land management to be transferred to a custodial authority. For mining tenure in Western Australia this would normally mean relinquishment to the State Government.

The accepted approach to relinquish mining tenure after closure works is to measure rehabilitation performance against agreed objectives and criteria over a period of time, in order to demonstrate success to key stakeholders (DMP \& EPA 2015).

\section{Current approach}

In Western Australia, as in other jurisdictions around the world, the State Government or relevant custodial authority may be unwilling to inherit the responsibility for managing closed mines and ongoing closure liabilities 'in perpetuity'. As such a mine operator can get caught in a cycle of post-closure maintenance, monitoring and reporting for a closed mine, with no agreed end point. 
There are very few examples in Western Australia where a closed mine has been relinquished to the State Government in a coordinated manner. Two exceptions are the Bottle Creek mine and Alcoa's Jarrahdale mine which were relinquished in 2001 and 2005 respectively (DITR 2006; Grant 2007).

There are, however, examples where State Governments in Australia have inherited legacy abandoned mines and their associated closure liabilities (DMP 2015). The Mining Rehabilitation Fund (MRF) has been introduced in Western Australia to help fund the rehabilitation of abandoned mines. The MRF is a pooled fund contributed to by Western Australian mine operators that hold tenure under the Mining Act 1978. MRF funds will be used to rehabilitate future abandoned mines and interest generated from the MRF shall be used to rehabilitate legacy abandoned mines (DMP 2015).

The current approach in planning for relinquishment of mining tenure could be improved to reduce long-term residual risks associated with closed mines and to develop adequate solutions to custodial transfer and management of closed mines.

\section{Concept to facilitate relinquishment of mining tenure}

Self-perpetuating funds and other mechanisms that buffer the exposure that a custodial authority has to residual liabilities and risks, in concert with demonstrated closure success, may encourage regulators including those in Western Australia to more readily consider relinquishment applications for mining tenure. The World Bank (2008) supports this concept and has recommended that self-perpetuating funds should be established for closed mines with long-term monitoring, maintenance and/or remediation requirements. Examples of such funds can be found in Queensland (Australia), Papua New Guinea, Indonesia, South Africa, Nevada (USA) and the European Union (World Bank 2008).

Self-perpetuating funds can provide financial surety in the event of foreseen or unforeseen closure risks, provide for organisation and management of a custodial body, provide an ongoing benefit to the community or the environment, and can fund ongoing security and maintenance for a closed mine. Examples of such initiatives can be found at the Ok Tedi, Kelian and Minahasa Raya mines as discussed in Section 3.1 of this paper.

Self-perpetuating funds can disburse interest annually whilst preserving the principal amount. Interest disbursements can be used by the custodial authority to perform functions required to maintain and secure the closed mine. The principal amount could be deployed if required, to respond to future environmental or social impacts. The size of a mine operator's contribution to such a funding initiative can be based upon estimates of risk cost for the closed mine, where the financial surety should adequately cover the potential risk cost.

For a mine operator the business case is strong: post-closure costs can be avoided via timely and coordinated relinquishment of mining tenure, in return for the establishment of or contribution to a funding initiative to support custodial transfer or other priority activities. For example, the operating expense for a modestly sized closed mine with no major environmental or social issues may exceed AUD 500,000 per annum. If a mine operator could reduce the post-closure period by 10 years; this would equate to a saving of AUD 5,000,000. Such an amount might make a more effectual contribution to the long-term management of a closed mine via a self-perpetuating funding arrangement.

The adoption of such an approach should be contingent upon the mine operator achieving very high mine closure and rehabilitation standards, and residual risks for a closed mine being minimised sufficiently to facilitate custodial transfer.

\subsection{Examples}

There are numerous examples from around the world where mine operators have established or plan to establish long-term, self-perpetuating funds as a mechanism to facilitate custodial transfer of mining areas and timely relinquishment of mining tenure. Examples from the Ok Tedi, Kelian and Minahasa Raya mines are presented below. 


\subsubsection{Ok Tedi mine}

The Ok Tedi mine is located in the upper catchment of the Fly River System in the Western Province of Papua New Guinea (PNG). The Ok Tedi mine produces copper and gold, and is operated by Ok Tedi Mining Limited (OTML). OTML have developed closure objectives and criteria to demonstrate closure performance to key stakeholders. The closure objectives and criteria form the basis of the relinquishment process and once they have been achieved, the Independent State of PNG will accept that closure risks have been sufficiently minimised and allow OTML to relinquish their mining tenure (Mackenzie et al. 2010).

OTML propose to establish two endowment funds to provide for basic security and maintenance of key areas after relinquishment. The endowment funds will be held in perpetuity and aim to provide for (a) basic long term security so that unauthorised access, clearing and excavation in rehabilitated areas are minimised and (b) basic long term maintenance of rehabilitated areas including surface water controls, erosion gullies and revegetation (Mackenzie et al. 2010).

Provision has been made for both endowment funds within OTMLs closure cost estimate. The size of each fund has been calculated so that a number of community members are paid a wage in return for providing basic security and maintenance for two key areas. Furthermore the principal amount could be accessed to fund a response to an impact after mine closure if required (Mackenzie et al. 2010).

The procedure for disbursements from these funds will involve annual checks to ensure that the community have been managing the land in accordance with the purpose of the funds. If the land has not been managed appropriately, disbursements will not be made. It is proposed that the clan members to be involved in this scheme will also be involved in closure and rehabilitation planning and implementation. The participants will therefore have the skills and knowledge to enable the concept to be effective (Mackenzie et al. 2010).

OTML included a risk based contingency and risk mitigation allowance within their closure cost estimate. The contingency allowance was calculated from an estimate of post-closure risk cost and likelihood. The mitigation allowance was calculated from an assessment of the cost-effectiveness of risk mitigation actions (Mackenzie et al. 2010).

\subsubsection{Kelian mine}

The Kelian mine (Kelian) was a large gold mine in East Kalimantan, Indonesia. Kelian was owned and operated by Kelian Equatorial Mining (KEM) and was closed in 2005. KEM aimed to relinquish the Contract of Work (COW) mining area to the State using monitoring data to demonstrate compliance with agreed closure objectives and criteria (OTML 2009).

KEM established a Closure Foundation to fund ongoing (a) forest protection and (b) community transition after relinquishment. The Closure Foundation Board was to comprise representatives from KEM and its owners, National and Local Government, and NGO/Academia (OTML 2009).

A forest protection endowment fund was established to provide for long-term monitoring, maintenance and protection of the COW area. PT Hutan Lindung Kelian Lestari (HLKL) was established as the post-closure institution to administer this fund. The role of PT HLKL was to coordinate monitoring, maintenance, forest protection and ranger patrols around the COW. The PT HLKL Board was to comprise representatives from the Provincial and National Government, KEM, an environmental NGO and from the community (OTML 2009).

A community transition endowment fund was established to support the community in the transition from a mining economy. Yayason Anum Lio (YAL) was established as the community foundation to administer this fund. YAL was focussed on the development and management of an agricultural school to teach students to grow food to support their families. The land and the school are owned by YAL and students attend the school free-of-charge. The fund provides for all operating and maintenance costs for the school (OTML 2009).

YAL were working to identify other local programs to support, including food security, health, culture and education (OTML 2009). 
The YAL Board was to comprise representatives from KEM and its owners, Local Government, an International Development Agency, a local NGO and the community. It was thought that over time the YAL foundation may receive additional funding from external donors and income generating projects (OTML 2009).

\subsubsection{Minahasa Raya}

Minahasa Raya (MR) was a gold mine located $80 \mathrm{~km}$ south of Manado in North Sulawesi, Indonesia. MR operated from 1996 until mine closure works were completed in 2004. MR aimed to relinquish the COW area to the State using monitoring data to demonstrate compliance with agreed closure objectives and criteria. MR established three foundations to fund ongoing (a) education, (b) economic activity and (c) community development and monitoring, after relinquishment of the COW area (OTML 2009).

The Minahasa Raya Foundation is an endowment fund that was established in 2000 to increase human development through scholarships, training and education. After 15 years the fund is still functioning and is considered successful (P. Soeprapto, personal communication, 19 August 2015).

The Ratatotok-Buyat Foundation was an endowment fund established from the sale of scrap steel from the mine. The aim of the fund was to provide for the economic sustainability of the local community. After approximately 10 years the fund is still functioning and is considered successful (P. Soeprapto, personal communication, 19 August 2015).

The North Sulawesi Sustainable Development Foundation was established to administer the 10 year Goodwill Agreement fund for community development and additional post-closure environmental monitoring from 2006 to 2016 . Approximately $84 \%$ of annual disbursements from the fund were allocated to community development and the remainder were allocated for environmental monitoring. The portion allocated to community development was used for infrastructure projects including hospitals and roads. The mine operator occupied one of ten positions on the Board of the North Sulawesi Sustainable Development Foundation (OTML 2009).

\section{Conclusion}

Self-perpetuating funds and other mechanisms that buffer the exposure that a custodial authority has to residual liabilities and risks, in concert with demonstrated closure success, may encourage regulators including those in Western Australia to more readily consider relinquishment applications for mining tenure.

Self-perpetuating funds can disburse interest annually whilst preserving the principal amount. Interest disbursements can be used by the custodial authority to perform functions required to maintain and secure the closed mine. The principal amount could be deployed, if required, to respond to future environmental or social impacts.

Post-closure costs can be avoided for a mine operator via timely and coordinated relinquishment of mining tenure, in return for the establishment of or contribution to a funding initiative to support custodial transfer or other priority activities. The size of a mine operator's contribution to such a funding initiative should be based upon estimates of risk, where the financial surety should adequately cover the potential risk cost.

The adoption of such an approach should be contingent upon very high mine closure and rehabilitation standards being achieved, and residual risks for a closed mine being minimised sufficient to facilitate custodial transfer.

\section{References}

DITR (Department of Industry, Tourism and Resources) 2006, Mine closure and completion - leading practice sustainable development program for the mining industry.

DMP (Department of Mines and Petroleum) 2015, Abandoned mines policy - draft for consultation.

DMP \& EPA (Department of Mines and Petroleum \& the Environmental Protection Authority) 2015, Guidelines for preparing mine closure plans.

Grant, C 2007, 'Developing completion criteria for Alcoa's bauxite mine rehabilitation in Western Australia - an iterative process', in A Fourie, M Tibbett \& J Wiertz (eds), Proceedings of the Second International Seminar on Mine Closure, Chile.

Mackenzie, S, Topurua, A \& Werror, M 2010, 'The Ok Tedi mine; applying good practice initiatives in planning for the closure of a large and complex mine', in A Fourie, M Tibbett \& J Wiertz (eds), Proceedings of the 5th International Conference on Mine Closure 2010, Chile.

OTML (Ok Tedi Mining Limited) 2009, Benchmark study report - findings from three mine visits, unpublished report, prepared by S Mackenzie.

World Bank 2008, Guidance notes for the implementation of financial surety for mine closure. 